\title{
SOBRE IDEOLOGÍA Y ESTÉTICA EN ÁNGEL GONZÁLEZ
}

Marta Beatriz FERRARI

Universidad Nacional de Mar del Plata

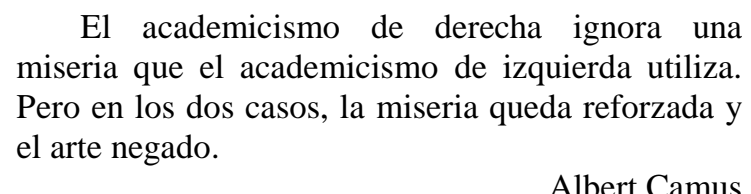

Doda vez que se piensa el tema del compromiso -y del compromiso literario, en particular- se reactualiza el conocido debate que en los años cincuenta tuvo

L lugar, en el corazón de la intelectualidad francesa, entre Jean-Paul Sartre y Albert Camus. Mario Vargas Llosa lo recuerda como «una célebre polémica del verano parisino de 1952 que tuvo como escenario las páginas de Les Temps Modernes y que opuso a los autores de La Náusea y La Peste, hasta entonces amigos y aliados y las dos figuras más influyentes del momento en la Europa que se levantaba de las ruinas» (Vargas Llosa, 1981: 7).

Frente a la cruda realidad de la época, Sartre no concebía la posibilidad de mantenerse neutral o indiferente, defendía, por lo tanto, la toma de partido, cosa que él hace en nombre del realismo y de la moral práctica; para Camus, en cambio, negarse a elegir entre dos clases de injusticia o de barbarie equivalentes era reivindicar para el hombre un destino superior al que las ideologías y los gobiernos querían reducirlo. Pero ambos compartían la misma fe en el poder de las palabras. Escribir era actuar; las palabras eran actos. El escritor comprometido sabe, según Sartre, que las palabras son pistolas cargadas. El escritor sentía la obligación cívica y social de participar en el debate intelectual, filosófico y político del momento. El escritor debía comprometerse.

En el mismo año 1952, en la España franquista, el editor y antólogo Francisco Ribes publicaba unas declaraciones que se convertirían más tarde en el slogan de la poesía llamada social. Me refiero a la poética con que Gabriel Celaya, haciéndose eco 
de los reclamos nerudianos de Caballo verde para la poesía, presentaba sus poemas en la célebre Antología Consultada:

La poesía no es un fin en sí. La poesía es un instrumento, entre nosotros, para transformar el mundo. En el poema debe haber barro. Debe haber ideas. Debe haber calor animal, y debe haber retórica, descripción, argumento, y hasta política. La poesía no es neutral [...]. Nada me parece tan importante en la lírica reciente como el desentenderse de las minorías y, siempre de espaldas a esa burguesía semiculta, el buscar contacto con unas desatendidas capas sociales que golpean urgentemente nuestras conciencias llamando a vida (Ribes, 1952: 78).

Camus describirá con absoluta claridad esta encrucijada ante la cual se encuentra el escritor a finales de los años cincuenta:

Nuestra época no admite que podamos desinteresarnos de ella. Los escritores de hoy lo saben. Si hablan, se los critica y se los ataca. Si se callan, ya no se hablará sino de su silencio para reprochárselo ruidosamente [...]. Desde el momento en que se considera la abstención misma como una elección, fustigada o alabada como tal, el artista, quieras que no, está embarcado. Embarcado me parece aquí más exacto que comprometido (Camus, 1958: 97).

El propósito del presente trabajo es, entonces, el de realizar una lectura de la poética gonzaliana comprendida en las dos décadas que van de los años cincuenta a los setenta, a la luz de algunas de las ideas arriba señaladas.

\section{1. «¿Es el arte un lujo mentiroso?»}

¡Oh, tú, extranjero osado que miras a los hombres: contempla las estrellas!

Ante la pregunta que él mismo se formula, si el arte es un lujo mentiroso, Camus se responde que, en efecto, el arte puede ser un lujo mentiroso, y añade: «En la toldilla de las galeras siempre y en todas partes se puede, lo sabemos, cantar a las estrellas mientras los forzados reman y se agotan en la cala» (1958: 102). Ángel González parece compartir plenamente esta idea. Su escritura nos permite formular dos grandes modelos poéticos frente a los cuales reacciona el sujeto y contra los cuales postulará su propia poética personal. El blanco de la crítica gonzaliana es, como veremos, un blanco móvil. Por un lado, pasa revista con una mirada profundamente crítica y una sanción descalificadora a la estética de los llamados «poetas puros». «Soneto a algunos poetas», por ejemplo, parece tomar como referente a los sucesores de la revista Garcilaso. En él se juega con adjetivos - precisamente aquellos que califican a la lexía 'palabras' como «oscuras» $\mathrm{y}$ «puras»- que nos remiten a una práctica esteticista como la de Juan Ramón Jiménez o al hermetismo surrealista de algunos exponentes del 27: «Todas vuestras palabras son oscuras». Por su parte, una expresión como «serena palidez» nos reenvía a los sonetos clásicos de Garcilaso y a la depurada perfección de los seguidores de Jorge 
Guillén. Prácticas poéticas que se muestran a juicio del sujeto inoperantes y desprovistas de todo sentido.

Paralelamente tiene lugar su condena a la estética culturalista de sus contemporáneos, los «novísimos». En su poemario de 1972 Muestra, corregida y aumentada, de algunos procedimientos narrativos y de las actitudes sentimentales que habitualmente comportan denunciará a la escritura «novísima» con su boato grandilocuente, como a una estética vacua y trasnochada, enunciada por anacrónicos vates que resucitan viejos modelos y en la cual el juego con las imágenes no pasa de ser un entretenimiento ornamental y gratuito: «Y se prueban metáforas como putas sostenes / ante el oval espejo de las oes pulidas / que la admiración abre en las bocas afines» (González, 1986: 308).

La conciencia del sujeto de pertenecer a un tiempo presente diferente y único será el motor que lo impulse en la búsqueda de las nuevas palabras; con mirada retrospectiva sentencia: «La lágrima fue dicha... No es bueno repetir lo que está dicho» (González, 1986: 47). Esta voluntad distanciadora lo preserva del mesianismo hímnico de sus inmediatos predecesores. El poema titulado precisamente «El momento este», emparentado tópicamente con el anterior refuerza el convencimiento de que la poesía del lamento y el llanto pertenece a un tiempo defintivamente ido: «En el aire quedaron vestigios de palabras: / -...supervivientes todos de inclinada postura: / sería / preferible / fallecer intentando enderezar los huesos...- / y pasó un aeroplano y ya no se oye nada» (González, 1986: 161; cursiva en el texto).

La crítica a los «poetas de la pureza» apunta a condenar una práctica estética desencarnada, la ejercida por aquellos que transitan por la superficie de las cosas sin penetrarla nunca, sin ahondar en lo real: «Imagen de la vida diminuta, / impresa a dos tintas, / plana» (González, 1986: 365). Incluso en libros posteriores habrá poemas en los que estos estetas genéricamente aludidos adquieran una identidad empíricamente verificable, tal es el caso del poema «J. R. J.», de Prosemas o Menos, cuyas iniciales nos envían directamente al autor de Eternidades. El sujeto textual degradará aquí el laborioso quehacer poético juanramoniano al asimilarlo con un oficio manual, una actividad de índole estrictamente mecánica: «apretaba las tuercas a un epíteto. / Luego engrasó un adverbio, / dejó la rima a punto, / afinó el ritmo / y pintó de amarillo el artefacto. / Al fin lo puso en marcha, y funcionaba» (González, 1986: 369). En el texto de González, el sujeto poético sigue siendo, como quería Jiménez, un artífice, un auténtico hacedor, lo que cambia, sin embargo, es el producto, ya no la «Obra» perfecta, intocable, sino el burdo poema-artefacto. El tantas veces citado texto juanramoniano «El poema»: «No le toques ya más / que así es la rosa», es paródicamente invertido en el texto de González: «-No lo toques ya más, / se dijo. / Pero / no pudo remediarlo: / volvió a empezar». 
Frente al desasosiego que genera el no poder aferrarse a algo que podamos considerar indubitablemente como real, se recurre a la prueba de evidencia y esa prueba no es otra que la evidencia del poema escrito o, más aún, del proceso mismo de su escritura: «De todas formas, tengo todavía / este papel, / la pluma / y la mano derecha que la aprieta / [...] / Pienso: / la tarde muere, / y mi mano escribe: / la tarde / muere». Pero el proceso que va del pensamiento al lenguaje sólo puede traducirse gráficamente en la pausa instalada al final del verso que alerta acerca del carácter temporalmente sucesivo de la escritura, resaltado con un uso distintivo de las itálicas. Por otra parte, el proceso de escritura poemática deliberadamente exhibido en todos sus pasos nos remite a una fuente que, lejos de asociarse a una matriz de inspiración suprarracional, concluye en una explicación burdamente científica del funcionamiento motriz de la mano que escribe guiada no por el rapto divino sino por «el perfecto funcionamiento de mis centros nerviosos / que transmiten las órdenes que emite mi cerebro / a las costas lejanas de mis extremidades» (González, 1986: 142). En declaraciones a Luna de Abajo, el autor ha manifestado su rechazo por la idea de «inspiración»:

\footnotetext{
Me resulta pretenciosa -afirma- porque alude a ciertas indeseables interferencias de los dioses en los trabajos humanos. Me gusta decir que escribo poesía a partir de algunas «ocurrencias», esta palabra, además de ser inofensiva, es desacralizadora, desmitificadora, deja el quehacer poético dentro de los límites naturales del hombre (VV. AA., 1985: 54-55).
}

Paralelamente, se despliega la acepción del quehacer poético como oficio; el oficio de escribir -dirá el sujeto- requiere permanecer fuera de la gran corriente de la vida, el poeta es quien busca y asedia lo real pero desde sus márgenes: «Inmóvil en la nada, al margen / de la vida (hundido / en un denso silencio sólo roto / por el batir oscuro de mi sangre), / busco, / busco aquellas palabras que no existen» (González, 1986: 178). Se trata, en buena medida, de un oficio ocioso, de un placer onanista puesto que lo que se busca se intuye ya, desde el comienzo, inexistente. En el texto ya citado, Camus se referirá a la poética del «arte por el arte» como al «entretenimiento de un artista solitario que termina por destruir toda realidad» (1958: 104).

En ocasiones, el sujeto vuelve nostálgicamente a evocar ese momento optimista de fe en la palabra. Es el momento en que la palabra recubre y contiene absolutamente a la realidad que nombra; entre ambos órdenes no existen grietas sino armoniosa y necesaria correspondencia. En este itinerario, desde su génesis hasta hoy, la palabra atravesó por diversas fases: ante todo fue palabra oral, después se fijó en su grafía, más tarde se convirtió en tópico literario en manos de autores consagrados. Pero el hablante poemático sabe de la imposibilidad de recuperar desde su presente aquel estadio originario: «Retrotraerse a un sentimiento puro, / imaginar un mundo en sus pre-nombres, / es imposible ahora» (González, 1986: 185). La palabra concebida al modo del simbolismo esteticista -cargada de ocultas significaciones, auténtico 
sortilegio verbal, creadora rítmica de la belleza- es, en la visión del sujeto poeta «la única palabra irrefrenable / que mi sangre entendía y pronunciaba: / una palabra para estar seguro, / talismán infalible / significando aquello que nombraba». Sin embargo, la quiebra acontece: sobreviene la ruptura de esos lazos que vinculaban mágicamente al lenguaje con lo real; perder la palabra significa también y al mismo tiempo perder la realidad que ella nombraba:

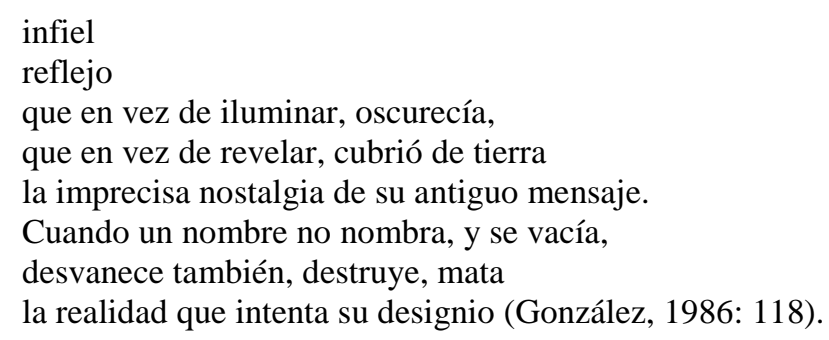

\title{
2. «El arte no puede ser un monólogo»
}

\author{
Porque la voz humana únicamente \\ es eficaz si encuentra \\ el cauce de un oído que quiera interpretarla
}

Una vez más, los versos de Ángel González parecen suscribir la afirmación de Albert Camus: «El ideal de la comunicación es el ideal de todo gran artista. El arte no puede ser un monólogo» (108). Su escritura poética tiende también a ese «tú», tantas veces buscado por los poetas sociales de los cuarenta, como Blas de Otero, por ejemplo, ese otro con quien conversar («el yo -dirá Otero-, por su misma configuración, deviene en hoyo, en vacío, al extrañarse del tú y quedar desterrado del nosotros»). Como para Otero, para quien «el poeta es un juglar o no es nada» y «si no se debe escribir como se habla, tampoco resulta conveniente escribir como no se habla» (De Otero, 1980: 37), para González el quehacer poético deberá encauzarse hacia un discurso «antipoético». Breves acotaciones para una biografía parece ser el libro en el que culmina este firme proceso de desacralización que veíamos preanunciado en textos anteriores. En él se opondrá a todo lo instituido -la poesía oficial-, cuestionará lo establecido y regulado como válido dentro del género, lo que corresponda a una normativa histórica. Se tratará de una poesía de fronteras abiertas en la que tienen cabida todos los discursos sociales, desde la publicidad hasta los graffitis callejeros. En esta misma línea desacralizadora ocupa un lugar central el «Manifiesto» antipoético de Nicanor Parra con su postulación de «la poesía de la plaza pública» escrita/conversada en «el lenguaje de todos los días». Recordemos que Poemas y antipoemas fue publicado en el año 1954, y que el mismo González reconoce el tardío descubrimiento de este «antipoeta»:

Hasta hace muy poco no había podido leer bien a un poeta tan famoso como Nicanor Parra. Gracias a una edición cubana cayó un ejemplar en mis manos y su lectura me produjo enormes satisfacciones, como observar afinidades y coincidencias entre él y yo 
[...]. Los antipoemas de Parra coinciden con mi intención de hacer poemas con materiales, con léxicos, muy poco poéticos. Me sorprendo ahora de vez en cuando haciendo algo que no quiero que parezca un poema; que lo sea, pero que no lo parezca. No podría explicarlo mejor, pero ese tipo de poemas sería como eructar en un banquete (Campbell, 1971: 370$371)$.

Sin embargo, la paradoja central de la escritura gonzaliana radica en que su programa antipoético con la propuesta extrema de formular una estética de la basura, de lo prohibido, de los restos, no pasa de ser sólo eso, una declaración de principios poéticos que nunca se traduce en práctica escrituraria. Porque resulta incuestionable, desde nuestra mirada de críticos de fin de siglo, que su poesía, aún en aquellos libros en los que el juego, el humor, la irreverencia y el desenfado parecen poner en peligro el lirismo de sus poemas, continúa siendo, en el sentido convencional del término, una «poesía poética».

Paralelamente, a partir de Sin esperanza con convencimiento, los poemas van convirtiéndose en terreno propicio para la insistente meditación acerca del conflictivo vínculo: lenguaje/cosa. El sujeto poemático pone permanentemente en cuestión la asignación definitiva, no problemática entre el nombre y lo que éste designa: «Pan significa pan; amor, espanto; / madera, eso; primavera, llanto; / el cielo, nada; la verdad, el hombre» (González, 1986: 93). Las vinculaciones entre ambos órdenes surgen, a su juicio, arbitrarias y, en muchas ocasiones, se ofrecen definiciones antonímicas, palabras que carecen de significado, otras que convocan la materialidad misma del objeto para ser completamente expresadas y otras aún, cargadas de un peso existencial que excede los estrechos límites del lenguaje. Su propuesta de apostar por una apropiación experiencial del objeto, sin mediación lingüística alguna, se acerca a la formulación que pocos años después realizará Guillermo Carnero: «Cuánto / más verdadera que cualquier pronombre / es esa luz que cuaja el aire en día!». En continuidad con el poema anterior, el titulado «Símbolo», retoma el problema del significado de las palabras y lo amplía hasta poner en cuestión todo tipo de lenguaje, desde el matemático hasta el pictórico, del escultórico al musical. Las nociones de sustitución y representación inherentes al término «símbolo» se traducen una vez más en la problemática relación entre las cosas y los arbitrarios signos que pretenden dar cuenta de ellas: «Símbolo, / oscuro disfraz / del destino. / Ocho quiere decir: / Amor. / Nueve, quién sabe!» para explicitarse en un llamado de alerta: «Cuidado! / Engañan las palabras, / las cifras, los sonidos. / Nada es lo que parece».

Si el lenguaje es mendaz - «Sucede, entonces, / que si habla, el hombre, aunque no quiera, miente» (González, 1986: 133)- y el poeta trabaja exclusivamente con palabras, surge, inexcusable, la necesidad de fijar el significado de los nombres; la estrategia escritural de González construye, entonces, un sujeto lexicógrafo que propone recurrir a las acepciones convencionalmente aceptadas de las cosas: «(Consúltense estos nombres 
en una enciclopedia: / galaxia, paralaje, azimut, Newton, auge)». La presunción de que cada palabra tiene o puede tener un significado diferente para cada lector lleva al sujeto a intercalar en su escritura las definiciones lexicográficas de los términos, desprovistas de todo matiz connotativo: «he aquí a las hormigas / (Hormigas: insectos himenópteros que viven / asociados. Véase también abejas)». Como vemos, González trabaja, en muchos de sus textos, con un lenguaje pretendidamente desnudo, desprovisto de ese plus significativo que pareció definir al lenguaje poético durante siglos.

Podríamos decir que así comienza la etapa constructiva de su poesía. La búsqueda es, en su inicio, tanteo en el vacío, aproximación a ciegas: «Me falta una palabra, una palabra / sólo»; la pieza faltante en el ajedrez de algún soneto con rima difícil: «Una palabra dadme, una sencilla / palabra que haga juego / con...». La actitud lúdica que guía este primer buceo en las posibilidades del lenguaje cede paso a la estricta necesidad de una palabra única e irreemplazable -«esa palabra»-, palabra que se pretende sanadora: «La necesito: No véis / que sufro?». Sin embargo la súplica acaba en fracaso: «Así no puedo». La imposibilidad de hallar «la palabra» se vincula estrechamente con esa segunda voz en contrapunto, voz alter ego del sujeto que acarrea los componentes más degradados de la realidad histórico-social del yo: las «mujeres sucias con su lento llorar», los «miles de muertos», «el hombre ceniciento», la «gente rota», realemas que avasallan y anulan toda posibilidad de escritura que no dé cuenta de esto mismo.

La firme convicción humanista de que la palabra poética para ser tal necesita, como sostiene Camus, «de un oído que sepa interpretarla» conduce a González a buscar ciertas «figuras» en las cuales encarnar el sinsentido de esa palabra sin eco. Se trata, en ocasiones, de una voz que nace de la soledad y la tristeza y contagia igualmente de tristeza y soledad a aquello que nombra; la escritura así concebida deviene un proceso autorreflejo que se vuelve tautológicamente sobre sí mismo: «Voz que soledad sonando / por todo el ámbito asola, / de tan triste, de tan sola, / todo lo que va tocando» (González, 1986: 29). En otro de estos textos se recrea la figura del «orador implacable y solitario», a través del cual se deja oír la voz oficial, la emanada desde la autoridad, en un ejercicio vanidoso de elocuencia y buen decir. Se trata, expresa el sujeto, de una voz sin eco; no hay nadie que la escuche. En estos textos nos enfrentamos a la palabra concebida ya no al modo celayano, en tanto «arma cargada de futuro», sino más bien como arma arrojada ciegamente contra un blanco invisible: «no importa que tu palabra / caiga / como una piedra sobre el agua / y se hunda». El breve minuto de la palabra contrasta violentamente con la dimensión oximorónica del «instante enorme del silencio» (González, 1986: 117). Una segunda figura acompaña a la del orador, se trata del «predicador injustamente perseguido». La mirada irónica del sujeto registra impiadosamente los vanos esfuerzos con que este nuevo personaje pretende deleitar a un público otra vez ausente, su impotente palabra redentora y su falsa persuasión: «Abrió la 
boca, y las venas / del cuello / se le hincharon, coléricas, / y los puños, / no colgando: izando / los brazos contraídos y tensos por la ira, / parecían dos martillos dispuestos / a demoler / la indiferencia donde se perdían / sus palabras» (González, 1986: 163).

El contrapunto viene dado por otros textos que retoman la reflexión en torno al poder de las palabras; a esa voz sin resonancias posibles, palabra orientada hacia la muerte, el sujeto-poeta contrapone su voz, palabra viva, aquella que es capaz de encontrar a su lector. En unas declaraciones del año 1987, González explicaba:

La poesía es una actividad colectiva. El poema sin lector es inconcebible, no existe. El poema necesita al lector para ser, para terminarse, para hacerse del todo. En esta coincidencia de coautores del poema, el que en esta ocasión tiene menos que decir soy precisamente yo. El autor del poema lo que hace es una propuesta, un texto; y esa Propuesta o ese texto exige la respuesta del lector (VV. AA., 1987: 52).

Sin embargo, y a pesar del incipiente cuestionamiento del vínculo lenguaje/ realidad, la buscada destrucción del lenguaje llevada a cabo por algunos representantes extremos de la poesía del setenta comporta, para González, un carácter «utópico, pedante y tonto», y agrega: «Tampoco la palabra es tan inoperante como ahora se quiere hacer ver. La palabra, al fin y al cabo, es una expresión del pensamiento, y si el pensamiento no mueve al mundo, yo no sé qué carajo lo mueve» (Claudin-González Calero, 1978: 52).

\title{
3. «La realidad del mundo es nuestra patria común»
}

\author{
Pero el futuro es diferente \\ al porvenir que se adivina lejos, \\ terreno mágico, dilatada esfera \\ que el largo brazo del deseo roza, \\ bola brillante que los ojos sueñan, \\ compartida estancia \\ de la esperanza y de la decepción, oscura \\ patria \\ de la ilusión y el llanto \\ que los astros predicen \\ y el corazón espera \\ y siempre, siempre, siempre está distante.
}

En un intento por compensar el transfuguismo de algunos compañeros de promoción, quienes ante el apogeo culturalista de los novísimos, a finales de los sesenta, intentaron desprenderse rápidamente el rótulo de «realistas», Ángel González, en cambio, reitera su fidelidad a la denominada «estética del compromiso»: «Yo siempre me he sentido muy cómodo en la definición de realismo, entendiendo la realidad no como una mímesis sino como un material a utilizar» (Puente, 1998: 35) ${ }^{1}$. La suya es, sin dudas, una escritura situada; situada en el «aquí» y en el «ahora». El título

\footnotetext{
${ }^{1}$ Cfr. declaraciones semejantes en Víctor García de la Concha, «Lecciones de cosas y otros poemas», $A B C$ (23 de enero de 1998), p. 13.
} 
de su primer poemario, del año 1956, define a la época como Áspero Mundo. En uno de los poemas de este libro leemos: «Aquí, Madrid, mil novecientos / cincuenta y cuatro: un hombre solo» (González, 1986: 17). Y poco antes se nos revelaba la identidad de la voz enunciante: «Para que yo me llame Ángel González» (González, 1986: 15). Mención del nombre propio que pretende desbaratar el artificio de una enunciación distante $^{2}$, tiempo y espacio discursivos coincidentes con el presente de la escritura. En él, la recurrente tematización de la muerte, del fracaso, de la miseria se corresponde, en paralelo, con la construcción de un sujeto escindido («Yo mismo / me encontré frente a mí en una encrucijada»), exiliado («no hay sitio para ti en el descampado / donde habitas»), prisionero de un ejército de derrotados (1968: 74), un sujeto menor que, como diría Víctor Botas unos años después-, yerra en la literatura y en la vida. Una concepción existencialista del hombre definido, una y otra vez, como «pasión inútil» (González, 1986: 75), «pasión fatal que como un árbol crece»(González, 1986: 101), ante la inexistencia de Dios (González, 1986: 76).

Pocos son los poemas que como «El campo de batalla»o «Penúltima nostalgia» aluden de modo directo al conflicto bélico español con lexías tan incuestionablemente denotativas como «combate», «lucha», «sangre», «alambradas», «gritos», «cadáveres», «hambre»o «asesinos». Menos significativos, aún, son los textos que en la línea del Lorca de Poeta en Nueva York o el Alberti de 13 bandas y 48 estrellas, denuncian como lo hace, por ejemplo, en «Perla de las Antillas» (Grado Elemental, 1962) la injusta opresión de los pueblos de América. Por el contrario, la elección de González se orienta más hacia la alusión velada, el símil o el registro decididamente irónico.

La primera convicción del sujeto gonzaliano es que si la palabra poética buscada existe realmente, ha de ser una palabra temporal, historizada, enlazando, de este modo, con aquella estética machadiana, de hondo compromiso cívico. Muchos son los poemas que tematizan la conciencia que se tiene de la validez relativa del quehacer poético, relatividad que depende de la circunstancia histórico-política en que se inscriben el hablante y su escritura: «Otro tiempo vendrá distinto a éste. / Y alguien dirá: / "Hablaste mal. Debiste haber contado / otras historias: / violines estirándose indolentes / en una noche densa de perfumes, / bellas palabras calificativas / para expresar amor ilimitado, / amor al fin sobre las cosas / todas"»(González, 1986: 69). Sin embargo, el sujeto reencarnado en un nuevo Quijote conciente de la inutilidad de todas sus empresas, elige

\footnotetext{
${ }^{2}$ El biografismo de su escritura halla su sustento en ciertas declaraciones del autor en las que apela a la identificación final entre sujeto textual y sujeto biográfico para explicar la razón por la que sigue escribiendo poesía después de sesenta años de «haber sufrido el contagio de la literatura»: «Me temo que, aunque siempre sostengo lo contrario, estoy cayendo en la tentación de creer que el poeta que mis versos configuran -ese personaje ilusorio que habla en los poemas- soy efectivamente yo, y que el acabamiento del poeta significaría mi propio acabamiento... porque me resisto a confinar en el pasado ese residuo de mí mismo, a desprenderme de ese yo que es otro, pero que ahora cuando los dos estamos acercándonos a un final inevitable, noto que me hace muchísima compañía». Revista El País (domingo, 11 de enero de 1998), p. 35.
} 
referir la historia de un fracaso: «estoy aquí, insomne, fatigado, velando / mis armas derrotadas, / y canto / todo lo que perdí: por lo que muero».

Pero la palabra que se pretende temporal, inmersa en su contexto histórico y dadora de testimonio, es una palabra en permanente riesgo de ser silenciada. Numerosos estudios críticos abordan a la ironía como la estrategia que más efectivamente logra burlar las restrictivas condiciones impuestas por la censura ${ }^{3}$. El irónico es, como se sabe, un discurso en el que se dice más de lo que dice el texto, tiene dos significados, uno literal y otro encubierto; el emisor irónico crea un receptor igualmente irónico, capaz de reconstruir un significado no formulado verbalmente. La preferencia por el registro irónico (precisamente por lo que éste comporta de duplicidad y relativismo), con su decir oblícuo, nos obliga, como lectores, como cómplices, a pactar con ese texto y a abocarnos a un proceso de «reconstrucción» por el cual sustituimos el significado aparente por el sugerido. El mismo González afirma acerca del correlato objetivo algo que vale igualmente para la ironía:

Lo que trata de hacer Eliot es, en cierto modo, lo que trató de hacer también Mallarmé: no nombrar directamente, evitar el lenguaje directo; lo que yo trataba entonces era no nombrar, pero porque estaba prohibido nombrar. Aunque no en nombre de los principios estéticos simbolistas, decir la palabra sin decirla. Entonces, para que esa palabra fuera subversiva hacía falta que el lector supiera de lo que iba. ${ }^{4}$

Cuando Camus analiza las posibilidades del realismo artístico denuncia la paradoja implícita en un arte que no puede describir la realidad sin, al mismo tiempo, practicar en ella una elección que la somete a la originalidad inherente a todo arte. A partir de esta premisa aborda la literatura rusa de la revolución y afirma que «el verdadero objeto del realismo socialista es justamente lo que aún no tiene realidad» (Camus, 1958: 91); su principio, entonces, está no en la realidad que conocemos, sino en la realidad que habrá de venir. Afirmación que resuena en estos versos de Grado Elemental: «Que en cierto modo, / creer con fuerza tal lo que no vimos / nos invita a negar lo que miramos» (González, 1986: 167). González denuncia, ya desde el título de su segundo libro, Sin esperanza con convencimiento, la falacia implícita en una fe depositada en un porvenir inexistente. «Frustrada espera» (González, 1986: 32), la esperanza es definida como «el quicio de una puerta / de la casa que fue desarraigada / de sus cimientos por los huracanes» (González, 1986: 194). Pero en el pensamiento gonzaliano existe una diferencia sustancial entre el «porvenir» («Te llaman porvenir /

\footnotetext{
${ }^{3}$ El apartado subtitulado «Fábulas para animales», del libro Grado Elemental constituye una muestra suficiente de lo que se viene señalando.

${ }^{4}$ Véase Villanueva (1983). Sobre esta astucia con la que los autores de la época supieron adecuar sus obras a las exigencias impuestas por la censura resultan interesantes las declaraciones de Luis Martín Santos, quien publica en la misma década de los sesenta su novela Tiempo de silencio, «en la actualidad la única árma con la que el autor cuenta para modificar una realidad insoportable es precisamente la de escribir una novela suficientemente hábil para que pase la censura y suficientemente real para que preocupe políticamente al lector» (cit. en Suarez Granda, 1989: 57).
} 
porque no vienes nunca»), que es sólo promesa, fe teológica que condena al hombre a la pasividad de una espera inútil («Te llaman: porvenir, / y esperan que tú llegues / como un animal manso») y el «futuro» («tiempo de verbo en marcha, acción, combate, / movimiento buscado hacia la vida»), ese mañana («mañana no será lo que Dios quiera») siempre conquistado ( «En esa línea estoy, en esa honda / trayectoria de lucha y agonía»), ese nuevo día que se espera «con el alma en vilo» y que justifica la existencia presente. Del porvenir así entendido al futuro hay la distancia que va del consentimiento a la rebelión. De este mismo tipo de rebeldía habla Camus en El hombre rebelde, precisamente el libro que desencadena la referida discordia con Jean Paul Sartre.

En 1965, en una entrevista publicada en Le Monde, de París, Sartre acabaría reconociendo: «La Náusea, frente a un niño que se muere de hambre, no tiene poder. No tiene peso alguno, no sirve para nada» (Vargas Llosa, 2001: 68); en el mismo año, Manuel Vázquez Montalbán afirmaba: «Creo que la poesía, tal como está organizada la cultura, no sirve para nada. Sospecho que no sirve para nada en ninguna parte. Creo que escribir es un ejercicio gratuito que satisface las necesidades de unos 2000 culturalizados progresistas» (De Luis, 1965: 9). A pesar de la lúcida e inquietante duda (o precisamente por ella), los diversos modos con que González ejerce su ineludible compromiso como escritor adquieren siempre la forma de una reflexión ideológica sobre la poesía, y, en última instancia, vienen a insistir en la pregunta que, por esos mismos años, formulara Julio Cortázar, en Rayuela: «Si la lucidez desemboca en la inacción ¿no se vuelve sospechosa, no encubre una forma particularmente diabólica de ceguera?» (Cortázar, 1968: 261). González cree que sí, que es esta lucidez inmovilizadora a la que el hombre está expuesto, la que hay que combatir con todos los medios al alcance, evitando la complicidad que encuentra sus justificaciones posmodernas en el fin de las ideologías y la muerte de las utopías, en el conformismo individualista y en la apatía de los acomodados. Frente a «tanta realidad abrumadora», no resulta arriesgado pensar que Ángel González bien podría haber suscripto aquellos versos con que Pablo Neruda cierra, precisamente en 1966, su Arte de Pájaros:

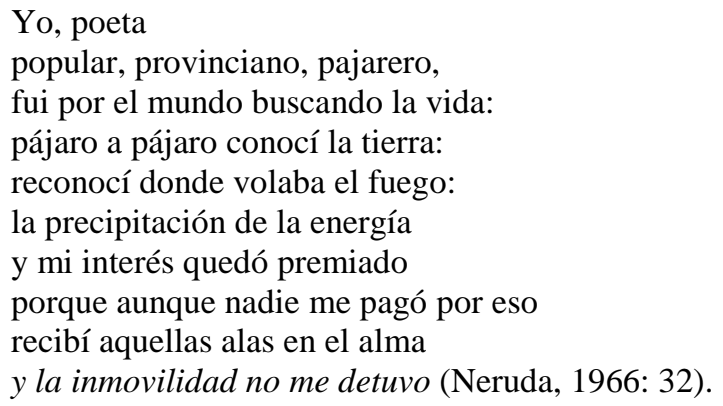


280 Tropelías. Revista de Teoría de la Literatura y Literatura Comparada, 19 (2013)

Marta Beatriz Ferrari

\section{Referencias bibliográficas}

CAMPBELL, Federico (1971): «Angel González o la desesperanza» (entrevista), en Infame Turba. Barcelona, Lumen, pp. 366-379.

CAMUS, Albert (1958): «El artista y su tiempo», en El revés y el derecho. Madrid, Alianza.

CLAUDIN, Víctor, y GONZÁLEZ CALERO, Alfonso (1978): «Angel González, poeta: Con esperanza, sin convencimiento» (entrevista), Zona, 36, septiembre.

CORTÁZAR, Julio (1968): Rayuela. Buenos Aires, Sudamericana.

DE LUIS, Leopoldo (1965): Antología de la poesía social. Madrid, Alfaguara.

DE OTERO, Blas (1980): Historias fingidas y verdaderas. Madrid, Alianza.

GONZÁleZ, Ángel (1986): Palabra sobre Palabra. Poesía 1956-1984. Barcelona, Seix Barral.

NERUDA, Pablo (1966): Arte de pájaros. Santiagode Chile, Sociedad de Amigos del Arte Contemporáneo.

PUENTE, Antonio (1998): «La Antología Lecciones de cosas de Angel González», El País (15-1-1998).

RIBES, Francisco, ed. (1952): Antología consultada de la joven poesía española. Santander, Marés.

SUÁREZ GRANDA, Juan Luis, ed. (1989): Luis Martín Santos, Tiempo de silencio. Madrid, Alhambra.

VARGAS LLOSA, Mario (1981): Entre Sartre y Camus. San Juan de Puerto Rico, Huracán.

(2001): Literatura y Política. México, Ariel.

VILLANUEVA, Tino (1983): «Censura y creación: dos poemas subversivos de Ángel González», Hispanic Journal, 5/1 (1983), pp. 49-72.

VV. AA. (1985): «Diálogo con uno mismo a través de cinco preguntas formuladas. Guía para un encuentro con Angel González», Luna de Abajo. Cuaderno de Poesía, 3.

(1987): Ángel González verso a verso. Libro Homenaje. Oviedo, Caja de Ahorros de Asturias. 